\title{
The Work Readiness Scale (WRS): Developing a measure to assess work readiness in college graduates
}

\author{
Catherine Lissette Caballero ${ }^{1}$, Arlene Walker ${ }^{2}$, Matthew Fuller-Tyszkiewicz ${ }^{2}$ \\ cathy.caballero@deakin.edu.au \\ ${ }^{1}$ Human Resources Services Division (Culture and Organisational Development), Deakin \\ University, and ${ }^{2}$ School of Psychology, Deakin University
}

\begin{abstract}
Work readiness is a relatively new concept which has emerged in the literature as a selection criterion for predicting graduate potential. Its definition and validity however, is contentious. To address this issue, the current study aimed to identify the attributes and characteristics that comprise work readiness and develop a scale to assess graduate work readiness. A qualitative study was conducted to assist in generating a representative pool of items for quantitative measurement. The resultant 167 item Work Readiness Scale (WRS) which we developed was validated in a sample of 251 graduates across a range of disciplines. Item analysis assisted in refining the scale. Exploratory factor analyses supported a four factor solution, with the final WRS consisting of 64 items. The four factors explained $44.7 \%$ of the variance, demonstrated excellent reliability and were labelled personal characteristics, organisational acumen, work competence, and social intelligence. The findings indicate that work readiness is a multidimensional construct and initial evidence is provided for the construct validity of the WRS.
\end{abstract}

Keywords: Work readiness, graduate employability, graduate recruitment, graduate selection, graduate assessment, transferable skills, graduate competencies.

\section{Introduction}

For many organisations, hiring graduates is a key source of new employee recruitment and a core component of human resource (HR) strategy (Rynes \& Boudreau, 1986; Slaughter, Stanton, Mohr, William, \& Schoel, 2005). As with all selection decisions, deciding on the skills and characteristics believed to be predictive of a graduate's job success is a vital consideration for organisations. Generally, the most common assessment methods used for selection in graduate recruitment include application forms, academic achievement, interviews (structured and unstructured), and cognitive ability tests (Carless, 2007; Hodgkinson \& Payne, 1998; Keenan, 1995). Academic achievement, in particular, has traditionally played a key role in graduate selection (Roth \& Bobko, 2000) and is used as a predictor of intellectual capability, capacity to learn, and motivation to pursue and achieve goals (ACNielsen Research Services, 2000). However, there is growing demand for graduates to possess a diverse range of generic attributes and skills for work (Hager \& Holland, 2006). A qualitative study by ACNielsen (2000) indicated that Australian employers value a range of personal attributes including enthusiasm, motivation, ambition, and personal presentation, which lie outside strict academic performance.

Work readiness is a relatively new concept which has emerged in the literature as a selection criterion for predicting graduate potential (ACNielsen Research Services, 2000; Casner-Lotto \& Barrington, 2006; Gardner \& Liu, 1997; Hart, 2008). Work readiness can be

Caballero, C., Walker, A., \& Fuller-Tyszkiewicz, M. (2011). The Work Readiness Scale (WRS): Developing a measure to assess work readiness in college graduates. 
defined as the extent to which graduates are perceived to possess the attitudes and attributes that make them prepared or ready for success in the work environment (Caballero \& Walker, 2010). The extent to which graduates are work ready is seen as indicative of potential in terms of job performance, success, and potential for promotion and career advancement (Atlay \& Harris, 2000; Casner-Lotto \& Barrington, 2006; Gabb, 1997; Gardner \& Liu, 1997; Hambur, Rowe, \& Luc, 2002; Hart, 2008; Stewart \& Knowles, 1999, 2000).

As a construct however, work readiness is still in its early stages of development and there appears to be a lack of clarity and consensus, first, regarding what is meant by work readiness, and second, with respect to the general skills and attributes that indicate work readiness (Casner-Lotto \& Barrington, 2006). Studies examining the work readiness of new graduate recruits from employers' perspectives (ACNielsen Research Services, 2000; Casner-Lotto \& Barrington, 2006; Gardner \& Liu, 1997; Hart, 2008) indicate that some graduates entering the workforce lack the preparedness and work readiness that is expected of them by employers, particularly in the areas of relational and personal competencies skills not directly taught in the classroom. The discrepancy between employer expectations and employer ratings of work readiness suggests that work readiness is not a criterion that is being examined effectively by current graduate assessment practices, if at all (Gardner \& Liu, 1997). In light of the importance being placed on work readiness as a selection criterion, it is evident that there is a growing need to systematically assess work readiness as a construct.

It is evident from studies that have examined the work readiness and performance of new graduate entrants (ACNielsen Research Services, 2000; Casner-Lotto \& Barrington, 2006; Gardner \& Liu, 1997; Hart, 2008) that variation exists in the generic skills and attributes articulated by employers as indicative of work readiness. Furthermore, different terms are used to refer to the same or similar attributes. For instance, 'generic skills' is used interchangeably with 'core skills', 'basic skills', 'transferable skills', and 'employability skills'. Similarly, different labels are used to describe the notion of work readiness including 'work preparedness', 'graduate employability', 'transferable skills', and 'generic attributes'. The inconsistent use of terminology might explain the difficulty in assessing the usefulness of work readiness across studies. (Atlay \& Harris, 2000; Casner-Lotto \& Barrington, 2006; Gabb, 1997; Gardner \& Liu, 1997; Hambur, et al., 2002; Hart, 2008; Stewart \& Knowles, 2000). Hence, as a first step towards a rigorous definition of work readiness, we attempt to develop a comprehensive measure of the attributes and characteristics of work readiness for graduate contexts.

A review of the literature identified one scale developed for a graduate population and relevant in an Australian context: the Graduate Skills Assessment (GSA). The GSA developed by the Australian Council for Educational Research assesses widely applicable generic skills acquired through university experience, such as written communication, critical thinking, problem-solving, and interpersonal understanding (Hambur, et al., 2002). However, the GSA does not directly assess personal attributes and capabilities, such as self -efficacy that may be associated with the application of generic skills. Furthermore, the GSA was primarily developed to provide an indicator to universities of generic skills in their students at entry/exit level, and as such, its effectiveness as a tool for assessing work readiness is contentious.

Current assessment methods used in graduate selection lack the rigour and construct validity required to effectively assess work readiness (see Caballero \& Walker, 2010 for a review of current graduate recruitment and selection methods). In Australia, organisations typically utilise three selection methods for graduate selection including application forms, interviews and cognitive ability tests (Carless, 2007). Literature on academic achievement suggests that university grades are related to general mental ability, with typical correlations

Caballero, C., Walker, A., \& Fuller-Tyszkiewicz, M. (2011). The Work Readiness Scale (WRS): Developing a measure to assess work readiness in college graduates. 
indicating a positive relationship of .05 (Jensen, 1980). However, Hart (2008) found employers do not support academic achievement as being effective in predicting work readiness and potential to succeed.

The validity of interviews in assessing work readiness is also doubtful. Traditionally, interviews have been designed to provide insight into future performance of the applicant based on their past experience. Hence, the validity of this method for graduates who lack job-related experience needs consideration. It is also unclear from the research whether employers adapt interviews for graduate contexts. One common refinement to the traditional interview format is to utilise future-oriented questions. However, Salgado (1999) argued that past-oriented questions demonstrate higher validity than future-orientated questions in selection interviews. The development of a scale designed to measure work readiness in graduate contexts could provide a systematic method of assessing the construct and may also assist in making more effective selection decisions.

The present research will explore work readiness using qualitative methodology and use the qualitative findings to develop a Work Readiness Scale (WRS). The specific objectives are to: (a) identify the attributes and characteristics of work readiness; (b) use the qualitative data to develop items for a WRS; and (c) pilot test the scale.

\section{Phase 1: Attributes and characteristics of work readiness}

A qualitative study was conducted to provide greater understanding and clarity of work readiness. Qualitative exploration of phenomena is becoming increasingly common, and is seen as a powerful technique (Patterson, 2001), particularly when integrated in the development of quantitative scales (Steckler, Kenneth, Goodman, Bird, \& McCormick, 1992). Two separate samples of participants were asked about their perceptions of work readiness and the various attributes and characteristics it comprises. Previous research and theory were also examined for attributes and characteristics which are indicative of work readiness.

\section{Participants}

A total of 30 participants (16 males and 14 females) participated in this study. Of the participants, nine (4 males, 5 females) were HR professionals with experience in the recruitment and/or assessment of graduate job applicants and 21 (12 males, 9 females) were graduate students who had recently been employed in a graduate program. Of the professional participants, $55.6 \%$ had experience in graduate recruitment and $77.8 \%$ had experience in graduate assessment, graduate induction, and graduate training. These participants had an average age of 36.7 years $(S D=11.3)$ and had worked an average of 5.2 years $(S D=2.42)$ in the graduate recruitment/assessment industry. Of the 21 graduate participants, $95.2 \%$ had completed an undergraduate degree at university. These participants had an average age of 23.2 years $(S D=1.9)$ and had an average of 2.19 years $(S D=1.03)$ work experience in their field of study.

\section{Procedure}

The qualitative study was conducted separately for the two participant groups. Participants in the HR sample were required to have a minimum of three years experience in the recruitment and/or assessment of graduate job applicants and were recruited through the personal business contacts of one of the researchers. Emails containing a plain language statement were sent to prospective participants inviting them to participate in a semistructured qualitative interview. The plain language statement assured anonymity and provided information regarding the general purpose of the study. Participants were also required to complete a consent form. Interviews were conducted face to face or over the

Caballero, C., Walker, A., \& Fuller-Tyszkiewicz, M. (2011). The Work Readiness Scale (WRS): Developing a measure to assess work readiness in college graduates. 
phone. Participants were asked about their perceptions of graduate work readiness with questions such as 'What do you believe makes a graduate student ready for work?' Demographic data such as age, gender, and work experience was also collected during the interview. The interviews were recorded and then transcribed verbatim.

A sample of recently employed graduates was chosen in order to obtain a holistic perspective of work readiness and as a means of counter-balancing employer and graduate perspectives. Graduate participants were sourced via an organisation with an established graduate recruitment program that utilises academic achievement, personality testing, cognitive ability testing, and interview procedures as part of its selection processes. Following negotiations with the organisation, one of the researchers attended a graduate induction program to conduct two focus group interviews with the graduates. The researcher was introduced at the beginning of each session and consent to participate in the focus group interview and have the proceedings tape recorded was obtained from the participants. The focus group interviews explored participants' perceptions of what it means to be 'work ready' and the attributes and qualities that make a graduate student ready for work with questions such as 'What characteristics do you think are most important for a work ready graduate?' Demographical data such as age, gender, and current course being completed was gathered prior to the focus group interview. The focus group interviews were taped and then transcribed verbatim.

\section{Analysis and results}

Thematic analysis of the 11 transcripts (9 semi-structured interviews, 2 focus group interviews) was undertaken using the qualitative data analysis software NVivo 2.0. To create categories for the thematic analysis, transcripts were read several times and text that showed commonalities between employer and graduate transcripts was initially isolated for category development. A list of broad categories was developed and expanded as the analysis progressed. To assign data to categories, text that closely resembled the category meanings was used as the unit of coding. The transcripts were initially coded using 16 broad categories identified in the data. Once the transcripts had been coded into the broad categories, text within each category was read and analysed to identify themes within categories.

To establish sufficient reliability to proceed with the analysis and interpretation of the data, a second researcher familiar with the aims and objectives of the research reviewed the data, categories and themes within categories. Discussions were then held between the two researchers to reach agreement over the final categories and themes. Refinement of the initial 16 categories, whereby categories were expanded, combined or re-named, resulted in 10 categories being established. The final 10 categories and underlying themes identified in the data are displayed in Table 1. 
Table 1. Coding categories and themes.

\begin{tabular}{|c|c|}
\hline Category & Themes \\
\hline Motivation & commitment, drive, persistence, achievement orientation \\
\hline Maturity & sense of responsibility/accountability, self awareness, mental/emotional maturity. \\
\hline $\begin{array}{l}\text { Personal growth/ } \\
\text { development }\end{array}$ & willingness to learn, openness to feedback, developmental insight \\
\hline $\begin{array}{l}\text { Organisational } \\
\text { awareness }\end{array}$ & $\begin{array}{l}\text { understanding of organisational structures, awareness of organisational culture, } \\
\text { rule/process conscious. }\end{array}$ \\
\hline Technical focus & $\begin{array}{l}\text { confidence in technical / theoretical knowledge, initiative, personal structure, task } \\
\text { management }\end{array}$ \\
\hline $\begin{array}{l}\text { Interpersonal } \\
\text { orientation }\end{array}$ & $\begin{array}{l}\text { communication skills, social confidence, collaboration/teamwork, building } \\
\text { relationships/engaging with others, social intelligence }\end{array}$ \\
\hline Attitudes to work & optimism, respect for others, realistic expectations, humility \\
\hline Problem solving & analytical/evaluative, decision making, ideas generation \\
\hline Adaptability & open to change (flexibility), acceptance of diversity, able to adapt behaviour \\
\hline Resilience & resilience to negative feedback, capacity to deal with competing work demands/challenges \\
\hline
\end{tabular}

\section{Phase 2: Development of the Work Readiness Scale}

To develop the categories and themes into items for the WRS, a process recommended by DeVellis (2003) was carried out. This included using simple language, avoiding ambiguities, and avoiding double-barrelled items. In addition, to avoid affirmation, acquiescence, or agreement bias, a combination of positively and negatively worded items were used. An eleven point rating scale $(0-10)$ anchored by Completely Disagree to Completely Agree was chosen for the scale for two reasons; first, it allows for greater levels of variance in the data (Dawes, 2001), and second, ratings out of ten are intuitively more meaningful than higher or lower ratings, which can impose greater cognitive load on respondents (Cummins, 2002). The qualitative data generated a pool of 180 items.

\section{Item Review}

The 180 items were reviewed by the nine HR experts who had significant experience in the recruitment and assessment of graduate applicants. Items were reviewed on the basis of whether they were indicative of work readiness by assigning a rating of yes, no, or unsure. Items that received a rating of no or unsure were either rewritten or eliminated from the item pool. For instance, the item 'I am able to fit into any social situation' was rewritten as 'Adapting to different social situations is one of my strengths'. As a result of this process, 167 items were retained and placed into a questionnaire for a pilot test of the scale.

\section{Participants}

A total of 251 participants (189 males and 62 females) participated in the pilot test of the measure. Participants were graduate job applicants applying for paid vacation positions as part of a graduate recruitment program. Participants represented a range of disciplines including engineering $(46.1 \%)$, science $(13.6 \%)$, commerce $(11.9 \%)$, business $(4.5 \%)$, accounting $(4.9 \%)$, finance $(2.1 \%)$, law $(3.7 \%)$, and combined business/science fields $(13.2 \%)$. The average age for the combined sample was 21.9 years $(S D=3.4)$, while the average years of education was $15.89(S D=1.73)$. Of the respondents, $54.3 \%$ had previous work experience in their field of study, with an average of 0.8 years work experience $(S D=0.88)$. 


\section{Procedure}

Approval was obtained from an organisation with an established graduate recruitment program to distribute the WRS to its prospective applicants as part of their online psychological testing process. Two hundred and eighty emails were distributed to the graduate job applicants with an attached plain language statement outlining the purpose of the study and login details for the online survey. Completion and submission of the questionnaire signified consent.

\section{Data Screening and Analytic Strategy \\ Data Cleaning}

Two hundred and fifty-one responses were received, giving a response rate of $90 \%$. Four surveys contained a large proportion of missing data and were removed from the analysis. The remaining 247 cases were inspected for outliers and out-of-range scores. Univariate outliers were detected for several items and, to reduce their influence, these scores were adjusted to 3.29 standard deviations from their respective means (Tabachnick \& Fidell, 2007).

\section{Scale Refinement}

Item analysis was conducted to detect items exhibiting floor or ceiling effects, heavy skew or low amounts of variance, all of which have been shown to produce spurious and/or unstable factor solutions (Nunnally \& Bernstein, 1994). Item-subscale total correlations were also inspected and items that had a correlation <.25 with their respective subscale were also deleted. This resulted in the deletion of 53 items. Bivariate correlations were conducted to check for presence of redundancy among the remaining 114 items and revealed that the highest correlation among items was .75. As such, no further items were deleted.

\section{Factor Analysis}

Initially, a confirmatory approach was adopted, in which the 10 factor solution derived from the qualitative findings was tested in AMOS v6. However, the proposed solution was inadmissible due to empirical under-identification (Kenny, 1979; Kenny \& Kashy, 1992), which was traced to highly multi-collinear latent variables in the model. Thus, exploratory factor analysis was used in the final analyses in order to provide a more parsimonious solution for the data set. Given prior indication that the factors of this WRS were related, the decision was made to submit the selected number of factors to maximum likelihood-based extraction with direct oblimin rotation. The Scree Plot and Kaiser-Guttman criterion (i.e., Eigenvalues greater than 1.0) were used to determine the number of factors to retain.

Oblique rotation has the advantage that it allows for assessment of the relationship between factors. In the event that at least some of the factors correlate with each other above .3, the factors were to be submitted to a further factor analysis with a Schmid-Leiman transformation (Schmid \& Leiman, 1957) to evaluate the existence and nature of higherorder factors in the data set. The Schmid-Leiman transformation permits researchers to evaluate the unique contributions of factors (within and across levels) for variables, thus easing interpretation of the factor structure. In essence, this method allows researchers to obtain: (1) direct contributions of higher order factors to the variables, and (2) relation of lower-order factors to variables which partial out the influence of higher-order factors (for a more detailed discussion, see Wolff \& Preising, 2005). Finally, variables were used for interpretation of the meaning of factors if their factor loading exceeded .45 ( Hair, Anderson, Tatham, \& Black, 1995). Items with loadings $\geq .45$ were also required to load at least .20 less on other factors in order to be considered as distinctive items. Items loading onto more than one factor were included in the factor with the highest loading, if the items were

Caballero, C., Walker, A., \& Fuller-Tyszkiewicz, M. (2011). The Work Readiness Scale (WRS): Developing a measure to assess work readiness in college graduates. 
distinctive or if there was theoretical reason for retaining the cross-loading item (Tabachnick \& Fidell, 2007). The stability of a factor was determined by the factor having at least three items loading onto it.

\section{Results}

\section{Factor Analyses}

A series of exploratory factor analyses with oblique rotation were conducted to determine a stable factor structure for the work readiness items. This iterative process resulted in a final solution with four factors accounting for $44.7 \%$ of the variance shared among the remaining 64 items. The four factors, which were all moderately related with each other, were submitted to a further factor analysis to assess the presence of higher-order factors. One factor was extracted and accounted for $42.5 \%$ of variance in the four, lower-order factors. The factor loadings onto this higher-order factor were strong, ranging from .56 to -.72 .

Table 2 shows the unique contributions of the first- and second-order factors and communalities for the 64 work readiness items following a Schmid-Leiman transformation of the lower order factor structure. Factor one accounted for $14.1 \%$ of the variance extracted by the factor solution. Twenty two items loaded onto this factor with the focus being on perceptions of personal characteristics related to work readiness. Items such as 'I sometimes experience difficulty starting tasks' and 'I don't like the idea of change' illustrate this factor. Nineteen items loaded onto factor two, which accounted for $16.1 \%$ of the explained variance. This factor appeared to be structured around organisational acumen and awareness of workplace practices and protocols. The factor is illustrated with items such as 'It is important to respect authority figures', 'At work it is important to always take responsibility for your decisions and actions' and 'It is important to learn as much as you can about the organisation'. Factor three related to work competence and accounted for $7.7 \%$ of the explained variance. The factor was measured by 15 items that had a focus on individuals' strengths and overall competence in relation to work. Items included 'I have a solid theoretical understanding of my field of work', 'I set high standards for myself and others' and 'One of my strengths is that I have an eye for detail'. Eight items loaded onto factor four, which accounted for $8 \%$ of the explained variance. This factor appeared to be structured around social intelligence and the extent to which individuals can adapt and interact in social work situations. The factor is illustrated with items such as 'Adapting to different social situations is one of my strengths', 'I can express myself easily', and 'Developing relationships with people is one of my strengths'. Finally, the single higher-order factor accounted for $54.1 \%$ of the variance explained by the first-order factors in the work readiness items. This general work readiness factor comprised the majority of items from each of these first-order factors, thus incorporating items reflecting personal characteristics, organizational awareness and acumen, work competence, and social intelligence.

Reliability analysis revealed that overall the WRS had good internal consistency, with a Cronbach's alpha value of .96. The four factors also had good internal consistency with a Cronbach's alpha value of .93 for Personal Characteristics (factor 1), .92 for Organisational Acumen (factor 2), .90 for Work Competence (factor 3), and .88 for Social Intelligence (factor 4). 
Table 2. Communalities and factor loadings for the Work Readiness Scale $(N=247)$

\begin{tabular}{|c|c|c|c|c|c|c|c|c|}
\hline Item & $\begin{array}{r}\text { General } \\
\text { Factor }\end{array}$ & $\begin{array}{r}\text { Factor } \\
1\end{array}$ & $\begin{array}{r}\text { Factor } \\
2\end{array}$ & $\begin{array}{r}\text { Factor } \\
3\end{array}$ & $\begin{array}{r}\text { Factor } \\
4\end{array}$ & $\mathrm{~h}^{2}$ Total $^{*}$ & $h^{2} G^{*}$ & $h^{2} 1 s^{*}$ \\
\hline Taking things personally & .45 & .08 & .11 & .00 & .44 & .42 & .21 & .21 \\
\hline Intolerance of critics & .55 & .13 & .26 & -.02 & .30 & .47 & .30 & .17 \\
\hline Stress when managing many things & .42 & .13 & .32 & -.08 & -.07 & .31 & .18 & .13 \\
\hline Averse to criticism & .31 & -.01 & .49 & .04 & -.06 & .34 & .10 & .24 \\
\hline $\begin{array}{l}\text { Comfort approaching senior people } \\
\text { at work }\end{array}$ & .49 & .25 & -.02 & -.04 & .34 & .42 & .24 & .18 \\
\hline Difficulty starting tasks & .50 & .17 & -.04 & -.18 & .27 & .38 & .25 & .14 \\
\hline Dealing with competing demands & .40 & -.08 & .02 & -.39 & .08 & .32 & .16 & .16 \\
\hline Easily offended & .42 & .06 & .52 & .10 & .08 & .46 & .18 & .29 \\
\hline $\begin{array}{l}\text { Unsure when appropriate to speak } \\
\text { up/stay quiet }\end{array}$ & .53 & .43 & .16 & .09 & .14 & .51 & .28 & .23 \\
\hline $\begin{array}{l}\text { Discomfort asking questions when } \\
\text { unsure }\end{array}$ & .47 & .42 & .03 & .02 & .12 & .41 & .22 & .19 \\
\hline $\begin{array}{l}\text { Overwhelmed by challenging } \\
\text { circumstances }\end{array}$ & .38 & -.02 & .37 & .00 & .13 & .30 & .14 & .16 \\
\hline $\begin{array}{l}\text { Don't like being told how to do } \\
\text { things differently }\end{array}$ & .68 & .13 & .15 & -.34 & .13 & 63 & .46 & .17 \\
\hline $\begin{array}{l}\text { Upset if others change the way I } \\
\text { have organised things }\end{array}$ & .68 & .15 & .20 & -.20 & .25 & 62 & .46 & .16 \\
\hline Managing new social situations & .45 & .22 & .32 & .05 & .03 & .36 & .20 & .16 \\
\hline $\begin{array}{l}\text { Difficulty understanding abstract } \\
\text { ideas }\end{array}$ & .53 & .47 & .03 & .05 & .17 & .53 & .28 & .25 \\
\hline $\begin{array}{l}\text { Don't think I will succeed with goals I } \\
\text { have set }\end{array}$ & .55 & .22 & .08 & -.06 & .32 & .46 & .30 & .16 \\
\hline Tendency to judge others & .52 & .08 & .37 & -.17 & -.06 & .45 & .27 & .18 \\
\hline $\begin{array}{l}\text { Superiority over others who have } \\
\text { less knowledge }\end{array}$ & .34 & .06 & .42 & -.01 & -.11 & .31 & .11 & .20 \\
\hline $\begin{array}{l}\text { Difficulty establishing trust and } \\
\text { rapport }\end{array}$ & .32 & -.08 & .48 & .04 & .06 & .34 & .10 & .24 \\
\hline Juggling too many things at once & .42 & .03 & .03 & -.10 & .40 & .35 & .18 & .17 \\
\hline Don't like the idea of change & .63 & .01 & .01 & -.61 & -.04 & .78 & .40 & .37 \\
\hline Don't like learning new things & .59 & .37 & .08 & -.05 & .18 & .52 & .35 & .18 \\
\hline Learning from your colleagues & .41 & .06 & .55 & .13 & .07 & .50 & .17 & .33 \\
\hline $\begin{array}{l}\text { Learning from employees who have } \\
\text { worked at an organisation for years }\end{array}$ & .59 & .45 & -.03 & -.06 & .19 & .58 & .34 & .24 \\
\hline $\begin{array}{l}\text { Learning from long serving } \\
\text { employees }\end{array}$ & .49 & .08 & .01 & -.16 & .35 & .39 & .24 & .16 \\
\hline $\begin{array}{l}\text { Understanding organisational } \\
\text { processes }\end{array}$ & .44 & .43 & -.05 & -.04 & .06 & .38 & .19 & .19 \\
\hline $\begin{array}{l}\text { Learning as much as you can about } \\
\text { the organisation }\end{array}$ & .59 & .35 & -.02 & -.13 & .22 & .54 & .35 & .19 \\
\hline Respecting colleagues & .57 & .10 & .05 & -.49 & -.11 & .60 & .33 & .27 \\
\hline Keeping abreast of business affairs & .51 & .43 & .09 & -.07 & -.06 & .46 & .26 & .20 \\
\hline $\begin{array}{l}\text { Taking responsibility for decisions } \\
\text { and actions }\end{array}$ & .36 & .35 & .03 & .00 & .01 & .25 & .13 & .12 \\
\hline Respecting authority figures & .60 & -.03 & .21 & -.26 & .29 & .55 & .36 & .19 \\
\hline Impact of world issues on business & .47 & .17 & -.06 & -.13 & .33 & .39 & .22 & .16 \\
\hline $\begin{array}{l}\text { Openness to opportunities to learn } \\
\text { and grow }\end{array}$ & .39 & .54 & -.05 & -.01 & -.12 & .46 & .16 & .30 \\
\hline Eager to throw myself into my work & .43 & .43 & .02 & .01 & .02 & .37 & .18 & .19 \\
\hline Always working on improving myself & .41 & -.11 & .60 & .01 & .04 & .55 & .17 & .38 \\
\hline $\begin{array}{l}\text { Organisation's values and beliefs } \\
\text { forms part of its culture }\end{array}$ & .61 & .27 & .09 & -.09 & .28 & .53 & .37 & .17 \\
\hline $\begin{array}{l}\text { Feedback as an opportunity for } \\
\text { learning }\end{array}$ & .49 & .38 & .11 & -.05 & -.01 & .39 & .24 & .16 \\
\hline
\end{tabular}

Caballero, C., Walker, A., \& Fuller-Tyszkiewicz, M. (2011). The Work Readiness Scale (WRS): Developing a measure to assess work readiness in college graduates.

Journal of Teaching and Learning for Graduate Employability, 2(2), 41 - 54. 


\begin{tabular}{|c|c|c|c|c|c|c|c|c|}
\hline Item & $\begin{array}{l}\text { General } \\
\text { Factor }\end{array}$ & $\begin{array}{r}\text { Factor } \\
1\end{array}$ & $\begin{array}{r}\text { Factor } \\
2\end{array}$ & $\begin{array}{r}\text { Factor } \\
3\end{array}$ & $\begin{array}{r}\text { Factor } \\
4\end{array}$ & $\mathrm{~h}^{2}$ Total ${ }^{*}$ & $h^{2} G^{*}$ & $h^{2} 1 s^{*}$ \\
\hline $\begin{array}{l}\text { Thrive on completing tasks and } \\
\text { achieving results }\end{array}$ & .50 & -.10 & .49 & -.12 & .09 & .52 & .25 & .27 \\
\hline $\begin{array}{l}\text { Can't wait to start work and throw } \\
\text { myself into a project }\end{array}$ & .62 & .02 & .07 & -.43 & .13 & .59 & .38 & .21 \\
\hline $\begin{array}{l}\text { Graduates need to be willing to start at } \\
\text { the bottom }\end{array}$ & .56 & -.02 & .44 & -.12 & .13 & .53 & .31 & .22 \\
\hline $\begin{array}{l}\text { Listening and learning is more } \\
\text { important than showing your } \\
\text { knowledge }\end{array}$ & .33 & .05 & .40 & -.03 & -.11 & .28 & .11 & .17 \\
\hline Confidence about learnt knowledge & .35 & .36 & -.03 & .00 & .07 & .26 & .13 & .13 \\
\hline $\begin{array}{l}\text { Solid theoretical understanding of field } \\
\text { of work }\end{array}$ & .42 & -.06 & .54 & -.03 & .02 & .48 & .18 & .30 \\
\hline People approach me for original ideas & .50 & .44 & -.05 & -.04 & .12 & .46 & .25 & .22 \\
\hline Confidence in technical competency & .56 & .11 & .10 & -.04 & .48 & .57 & .31 & .26 \\
\hline $\begin{array}{l}\text { Awareness of strengths and } \\
\text { weaknesses }\end{array}$ & .51 & .13 & .37 & -.05 & .04 & .42 & .26 & .16 \\
\hline Remain calm under pressure & .502 & -.05 & .42 & -.05 & .23 & .49 & .25 & .24 \\
\hline $\begin{array}{l}\text { Being successful at work is very } \\
\text { important }\end{array}$ & .52 & .02 & .48 & -.04 & .11 & .52 & .27 & .24 \\
\hline $\begin{array}{l}\text { Ability to apply learnt knowledge in } \\
\text { workplace }\end{array}$ & .41 & .42 & .00 & .00 & .04 & .35 & .17 & .18 \\
\hline Coping with multiple demands & .60 & .12 & .38 & -.15 & .03 & .54 & .36 & .18 \\
\hline $\begin{array}{l}\text { Set high standards for myself and } \\
\text { others }\end{array}$ & .53 & .05 & .42 & -.15 & -.02 & .49 & .28 & .20 \\
\hline $\begin{array}{l}\text { Analysing and solving complex } \\
\text { problems }\end{array}$ & .59 & .21 & .04 & -.31 & .04 & .50 & .35 & .15 \\
\hline Passion about field of study/work & .53 & .57 & .04 & -.02 & -.07 & .62 & .29 & .33 \\
\hline $\begin{array}{l}\text { Being the best in the field is very } \\
\text { important }\end{array}$ & .34 & .14 & .37 & -.04 & -.21 & .32 & .12 & .20 \\
\hline Have an eye for detail & .53 & .01 & .47 & -.14 & -.02 & .52 & .28 & .24 \\
\hline Have a mature view of life & .59 & .35 & .19 & -.08 & .03 & .51 & .35 & .17 \\
\hline Adapting to different social situations & .47 & .11 & .09 & -.06 & .34 & .36 & .22 & .14 \\
\hline Developing relationships with people & .39 & .35 & .04 & -.04 & -.02 & .28 & .15 & .13 \\
\hline Open and friendly approach & .39 & .09 & .36 & -.11 & -.15 & .32 & .15 & .17 \\
\hline Can express myself easily & .40 & -.02 & -.02 & -.35 & .11 & .30 & .16 & .14 \\
\hline Good at making impromptu speeches & .33 & .53 & -.03 & .01 & -.20 & .44 & .11 & .32 \\
\hline Adapt easily to new situations & .57 & -.02 & .06 & -.31 & .32 & .53 & .33 & .20 \\
\hline Reading body language & .50 & .12 & .07 & -.14 & .27 & .36 & .25 & .11 \\
\hline Working in groups & .59 & .06 & .01 & -.62 & -.18 & .77 & .35 & .42 \\
\hline Cronbach's $\alpha$ & .96 & .93 & .92 & .90 & .88 & & & \\
\hline
\end{tabular}

\begin{tabular}{|lrrrrrr|}
\hline Sum of squared loadings & Factor 1 & Factor 2 & Factor 3 & Factor 4 & General F & Total \\
\hline $\mathrm{h}^{2 *}$ & 4.08 & 4.66 & 2.23 & 2.31 & 15.65 & 28.92 \\
$\%$ & 14.1 & 16.1 & 7.7 & 8.0 & 54.1 & \\
\hline
\end{tabular}

\begin{tabular}{|l|l|}
\hline $\begin{array}{l}\text { Percentage of extracted variance } \\
\text { explained by the general factor }\end{array}$ & $54.1 \%$ \\
\hline $\begin{array}{l}\text { Percentage of extracted variance } \\
\text { explained by first-order factors }\end{array}$ & $45.9 \%$ \\
\hline
\end{tabular}

Note: ${ }^{*} h^{2}=$ variance extracted from items, $h^{2} 1 s t=$ variance extracted by first level factors, $h^{2} G=$ variance extracted by the higher level factor, $h^{2}$ Total $=$ the sum of $h^{2} G$ and $h^{2} 1$ st. 


\section{Discussion}

The purpose of this study was to identify the attributes and characteristics of work readiness using qualitative methods and to then develop a scale to quantify work readiness in graduate populations. The qualitative data identified ten broad categories indicative of work readiness including; motivation, maturity, personal growth/development, organisational awareness, technical focus, interpersonal orientation, attitudes to work, problem-solving, adaptability, and resilience. The ten broad categories informed the development of an initial 167 item WRS. Following a pilot test of the measure a 64 -item, four factor solution was obtained and psychometric analyses indicated high reliability for all factors. The final four factors were labelled personal characteristics, organisational acumen, work competence, and social intelligence.

The results of this study and the final four factor structure support the notion that work readiness is a multidimensional construct (Atlay \& Harris, 2000; Casner-Lotto \& Barrington, 2006; Gabb, 1997; Gardner \& Liu, 1997; Hambur, et al., 2002; Hart, 2008; Stewart \& Knowles, 2000). These results, however, do not support the ten broad categories identified in the qualitative study as being distinct factors of work readiness. In examining the four factor structure, it is evident that the final scale did not eliminate any of the original ten categories, but rather collapsed them into the final four factors. For instance, within the personal characteristics factor, items that were originally developed to assess resilience, adaptability, and personal development have been retained. The organisational acumen factor comprises items aimed at assessing motivation, maturity, organisational awareness, personal development, and attitude to work. Furthermore, work competence consists of items measuring technical focus, motivation, and problem-solving. Finally, in the social intelligence factor, items designed to assess interpersonal orientation and adaptability were retained in the final questionnaire.

The final four factors share similarities with attributes and characteristics suggested in the literature as being indicative of workforce readiness, work preparedness, and graduate transferable skills and qualities (graduateness) (Atlay \& Harris, 2000; Casner-Lotto \& Barrington, 2006; Gabb, 1997; Gardner \& Liu, 1997; Hambur, et al., 2002; Hart, 2008; Stewart \& Knowles, 2000). For instance, some of the skills and attributes which are closely tied in with the personal characteristics factor include personal skills (Gardner \& Liu, 1997), self direction (Casner-Lotto \& Barrington, 2006), self knowledge and adaptability (Hart, 2008), and flexibility (Gabb, 1997). Organisational acumen shares common elements with competencies such as professionalism/work ethic, ethical judgement, social responsibility, and global knowledge (Casner-Lotto \& Barrington, 2006; Hart, 2008), motivation (Gabb, 1997; Hambur, et al., 2002; Stewart \& Knowles, 1999), and lifelong learning/self direction (Casner-Lotto \& Barrington, 2006). Aligned with the work competence factor are competencies such as organisational ability, critical thinking, problem-solving, and creativity/innovation (Casner-Lotto \& Barrington, 2006; Gardner \& Liu, 1997). Similarly, social intelligence appears consistent with concepts identified in the literature such as teamwork/collaboration (Casner-Lotto \& Barrington, 2006; Gardner \& Liu, 1997), interpersonal/social skills, adaptability, and communication skills (Casner-Lotto \& Barrington, 2006; Gabb, 1997; Gardner \& Liu, 1997; Hambur, et al., 2002; Stewart \& Knowles, 1999, 2000).

In comparing the final WRS with the GSA measure developed by the Australian Council for Educational Research (Hambur, et al., 2002), similarities are also evident. The GSA assesses students' generic skills including Written Communication, Critical Thinking, Problem-Solving, and Interpersonal Understandings. These generic skill areas seem to be encompassed within the work competence and social intelligence factors of the WRS.

Caballero, C., Walker, A., \& Fuller-Tyszkiewicz, M. (2011). The Work Readiness Scale (WRS): Developing a measure to assess work readiness in college graduates. 
However, the personal characteristics and organisational acumen factors appear to be unique to the WRS. These findings support the assertion that as a measure of work readiness, the GSA might not be an effective and valid assessment tool.

The results of this study also highlight the ineffectiveness of the current assessment methods most commonly used in assessing work readiness in graduates. The findings indicate that work readiness is a multidimensional construct, and hence the use of current assessment methods which have not been specifically designed to assess work readiness in a graduate context is questionable.

With further validation and development the WRS could provide graduate employers with a systematic method of assessing the multidimensional construct of work readiness. However, like many employment selection methods, i.e. interviews, personality and integrity tests, the WRS is a self-report measure. As such, various biases may affect the results including the over reporting of good behaviours/attitudes and under reporting of less desirable behaviours/attitudes. It is for this reason that recruitment and selection processes should utilise multiple assessment methods in combination (Converse, Peterson \& Griffith, 2009). Encompassed within a battery of selection methods, the WRS could be an effective tool to provide a more rounded assessment of graduate's work readiness.

The goal of this study has been accomplished in that support has been found for the construct validity of the WRS. However, it should be noted that the process of validating a construct is often on-going and that no measure can be said to be validated in a final sense. It can be argued that it takes time and numerous empirical studies to provide evidence for the validity of a particular measure (Nunnally \& Bernstein, 1994). As such, the results of the current study constitute initial evidence of the construct validity of the WRS.

Although this study has made an incremental contribution to the graduate recruitment and selection literature, several limitations must also be noted. It could be argued that the methods used for data collection and sampling in the pilot test may not have fully captured the nature of work readiness. In particular, the gender imbalance of $75 \%$ males and $25 \%$ females may have impacted the findings. In addition, the participants were graduate recruits for a specific organisation, resulting in $46.1 \%$ of the sample being graduates with an engineering background. Whilst other disciplines were also represented in the participant sample, the high proportion of graduate engineers may also have impacted the findings. With regard to personal characteristics and attributes, it is expected that these could vary across disciplines and occupational groups. As such, future studies might consider recruiting graduate participants from a cross-section of disciplines and occupational groups.

A further limitation of this study is that participants responded to the WRS as part of a graduate recruitment program. Although participation was voluntary and graduates were advised that completing the WRS would not impact their employment, social desirability bias may have influenced the manner in which the graduates responded to the items. Future research could recruit graduate participants as part of a university initiative. This may eliminate the tendency for graduates to respond to items in a manner they believe employers might perceive favourably.

To date, empirical research on work readiness has been scant. One explanation for the limited research might be that, as a construct, work readiness is still in its infancy. The results of this study provide some support for the attributes and characteristics researchers have previously identified as indicative of work readiness. While measures have been developed to assess some of the individual attributes thought to constitute work readiness, such as motivation, it has also been argued that measures that take into account families or

Caballero, C., Walker, A., \& Fuller-Tyszkiewicz, M. (2011). The Work Readiness Scale (WRS): Developing a measure to assess work readiness in college graduates. 
clusters of behaviours may provide a more reliable and valid measure of an underlying theoretical construct (Fisher \& Locke, 1992). Broad, comprehensive measures are also believed to assist in better understanding underlying constructs (Fisher \& Locke, 1992). Therefore, investigating the broader construct of graduate work readiness, rather than dissecting the construct into individual behaviours and attempting to assess these, may provide researchers and practitioners with a clearer perspective on the dimensions of work readiness and ultimately provide a more effective and valid measure for its assessment.

This study provides a sound foundation on which to continue building and refining the construct of work readiness. The aim was to validate the scale items using item analysis. Future research could also consider the range of responses and scoring of the WRS across disciplines or occupational groups. Work readiness is a concept believed to be applicable to all types of graduates, however differences in scoring and the manner in which scores are interpreted could be expected for different occupational groups and/or work contexts. Another area for future research would be to compare graduates' ability versus employerbased measures of work readiness for predicting job performance, job satisfaction and person-environment fit. 


\section{References}

ACNielsen Research Services (2000). Employer satisfaction with graduate skills: Research report, Evaluations and Investigations Programme Higher Education Division. Canberra, ACT: Department of Education, Training and Youth Affairs

Atlay, M., \& Harris, R. (2000). An institutional approach to developing students' 'transferable' skills. Innovations in Education and Training International, 37(1), 76-84.

Caballero, C., \& Walker, A. (2010). Work readiness in graduate recruitment and selection: A review of current assessment methods. Journal of Teaching and Learning for Graduate Employability, 1(1), 13 - 25.

Carless, S. A. (2007). Graduate recruitment and selection in Australia. International Journal of Selection and Assessment, 15(2), 153-166.

Casner-Lotto, J., \& Barrington, L. (2006). Are they really ready to work? Employers' perspectives on the basic knowledge and applied skills of new entrants to the 21st century U.S. workforce. USA: The Conference Board, Inc., the Partnership for 21st Century Skills, Corporate Voices for Working Families, and the Society for Human Resources Management.

Converse, P.D., Peterson, M.H., \& Griffith, R.L. (2009). Faking on personality measures: Implications for selection involving multiple predictors. International Journal of Selection and Assessment, 17(1), 47-60.

Cummins, R. A. (2002). Vale ComQol: Caveats to the comprehensive quality of life scale Retrieved 4 August, 2009, from: http://acqol.deakin.edu.au/instruments/ValeComQol.doc.

Dawes, J. (2001). Comparing data gathered using five point vs eleven point scales. Paper presented at the Australia New Zealand Marketing Academy Conference Auckland, New Zealand, 1-5 December 2001.

DeVellis, R.F. (2003). Scale development: Theory and applications. Thousand Oaks, USA: Sage Publications.

Fisher, C. D., \& Locke, E. A. (1992). The new look in job satisfaction research and theory. In C. J. Cranny, P. C. Smith, \& E. F. Stone (Eds.), Job satisfaction (pp. 165-194). New York: Lexington Books.

Gabb, A. (1997). University challenge. Management Today. ( 1 December 1997), 62-64.

Gardner, P. D., \& Liu, W.-Y. (1997). Prepared to perform? Employers rate work force readiness of new grads. Journal of Career Planning \& Employment, 57(3), 32-56.

Hager, P., \& Holland, S. (2006). Introduction. In P. Hager \& S. Holland (Eds.), Graduate attributes, learning and employability. The Netherlands: Springer.

Hair, J. F., Anderson, R. E., Tatham, R. L., \& Black, W. C. (1995). Multivariate data analysis (4th ed.). Englewood Cliffs: Prentice Hall.

Hambur, S., Rowe, K., \& Luc, L. T. (2002). Graduate skills assessment: Stage one validity study. Report by Australian Council for Educational Research (ACER) for Evaluations and Investigation Programme. Canberra, ACT: Commonwealth Department of Education, Science \& Training.

Hart, P. D. (2008). How should colleges assess and improve student learning? Employers' views on the accountability challenge, $A$ survey of employers conducted on behalf of: The Association of American Colleges and Universities. Washington, DC: Peter D. Hart Research Associates, Inc.

Caballero, C., Walker, A., \& Fuller-Tyszkiewicz, M. (2011). The Work Readiness Scale (WRS): Developing a measure to assess work readiness in college graduates. 
Hodgkinson, G. P., \& Payne, R. L. (1998). Graduate selection in three European countries. Journal of Occupational and Organizational Psychology, 71(4), 359-365.

Jensen, A. R. (1980). Bias in mental testing. New York: Free Press.

Keenan, T. (1995). Graduate recruitment in Britain: A survey of selection methods used by organizations. Journal of Organizational Behaviour, 16(4), 303-317.

Kenny, D. A. (1979). Correlation and causality. New York: Wiley.

Kenny, D. A., \& Kashy, D. A. (1992). Analysis of the multitrait-multimethod matrix by confirmatory factor analysis. Psychological Bulletin, 112(1), 165-172.

Nunnally, J. C., \& Bernstein, I. H. (1994). Psychometric Theory (3rd ed.). New York: McGraw-Hill.

Patterson, F. (2001). Developments in work psychology: Emerging issues and future trends. Journal of Occupational and Organizational Psychology, 74(4), 381-390.

Roth, P. L., \& Bobko, P. (2000). College grade point average as a personnel selection device: Ethnic group differences and potential adverse impact. Journal of Applied Psychology, 85(3), 399-406.

Rynes, S. L., \& Boudreau, J. W. (1986). College recruiting in large organizations: Practice, evaluations, and research implications. Personnel Psychology, 39(4), 729-757.

Salgado, J. F. (1999). Personnel selection methods. In C. L. Cooper \& I. T. Robertson (Eds.), International Review of Industrial \& Organizational Psychology. New York: Wiley.

Schmid, J., \& Leiman, J. N. (1957). The development of hierarchical factor solutions. Psychometrika 22(1), 53-61.

Slaughter, J. E., Stanton, J. M., Mohr, D. C., William, A., \& Schoel, I. (2005). The interaction of attraction and selection: Implications for college recruitment and Schneider's ASA model. Applied Psychology: An International Review, 54(4), 419-441.

Steckler, A., Kenneth, R., McLeroy, K.R., Goodman, R. M., Bird, S. T., \& McCormick, L. (1992). Toward integrating qualitative and quantitative methods: An introduction. Health Education Quarterly, 19(1), 1-8.

Stewart, J., \& Knowles, V. (1999). The changing nature of graduate careers. Career Development International, 4(7), 370-383.

Stewart, J., \& Knowles, V. (2000). Graduate recruitment and selection practices in small businesses. Career Development International, 5(1), 21-38.

Tabachnick, B. G., \& Fidell, L. S. (2007). Using multivariate statistics (4th ed.). Boston: Allyn and Bacon.

Wolff, H., \& Preising, K. (2005). Exploring item and higher order factor structure with the Schmid-Leiman solution: Syntax codes for SPSS and SAS. Behavior Research Methods, 37(1), 48-58. 